\title{
Organizational coordination in sustainable humanitarian supply chain: an evolutionary game approach
}

Congdong Li, Fanshun Zhang, Cejun Cao, Yang Liu and Ting Qu

The self-archived postprint version of this journal article is available at Linköping University Institutional Repository (DiVA):

http:// urn.kb.se/ resolve?urn=urn:nbn:se:liu:diva-154513

N.B.: When citing this work, cite the original publication.

Li, C., Zhang, F., Cao, C., Liu, Y., Qu, T., (2019), Organizational coordination in sustainable humanitarian supply chain: an evolutionary game approach, J ournal of Cleaner Production, 219, 291303. https:// doi.org/ 10.1016/j.jclepro.2019.01.233

Original publication available at:

https:// doi.org/ 10.1016/j.jclepro.2019.01.233

Copyright: Elsevier

http://www.elsevier.com/

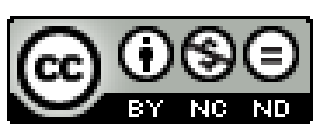


Organizational coordination in sustainable humanitarian supply chain: an evolutionary game approach

Congdong Li ${ }^{\text {a, b }}$, Fanshun Zhang ${ }^{\text {a }}$, Cejun Cao ${ }^{\text {c, b, ** }}$, Yang Liu ${ }^{\text {c, d, e, }{ }^{* *}}$, Ting Qu ${ }^{\text {c }}$

${ }^{a}$ School of Management, Jinan University, Guangzhou, 510632, China

${ }^{\mathrm{b}}$ College of Management and Economics, Tianjin University, Tianjin, 300072, China

${ }^{c}$ Institute of Physical Internet, School of Electrical and Information Engineering, Jinan University (Zhuhai Campus), Zhuhai, 519070, China

${ }^{d}$ Department of Management and Engineering, Linköping University, SE-581 83 Linköping, Sweden

${ }^{\mathrm{e}}$ Department of Production, University of Vaasa, 65200 Vaasa, Finland

* Corresponding authors: caocejun0601@tju.edu.cn (C.J. Cao), yang.liu@liu.se (Y. Liu) 


\section{Word count: 9568}

\section{Organizational coordination in sustainable humanitarian supply chain: an evolutionary game approach}

Congdong $\mathrm{Li}^{\mathrm{a}, \mathrm{b}}$, Fanshun Zhang ${ }^{\mathrm{a}}$, Cejun Cao ${ }^{\mathrm{c}, \mathrm{b},{ }^{*}}$, Yang Liu ${ }^{\mathrm{c}, \mathrm{d}, \mathrm{e},{ }^{* *}}$, Ting Qu ${ }^{\mathrm{c}}$

${ }^{a}$ School of Management, Jinan University, Guangzhou, 510632, China

${ }^{\mathrm{b}}$ College of Management and Economics, Tianjin University, Tianjin, 300072, China

${ }^{c}$ Institute of Physical Internet, School of Electrical and Information Engineering, Jinan University (Zhuhai Campus), Zhuhai, 519070, China

${ }^{\mathrm{d}}$ Department of Management and Engineering, Linköping University, SE-581 83 Linköping, Sweden

${ }^{\mathrm{e}}$ Department of Production, University of Vaasa, 65200 Vaasa, Finland

* Corresponding authors: caocejun0601@ tju.edu.cn (C.J. Cao), yang.liu@liu.se (Y. Liu)

Abstract: Sustainable humanitarian supply chain has a great impact on saving lives, decreasing human suffering and contributing to development. Organizational coordination plays an important role in it, although it is uncommon to be established due to the conflicting interests and expectations. To cope with the problem and achieve the sustainability of humanitarian supply chain, the coordination between private sector and humanitarian organization was further discussed with the help of sustainable principle regarding stakeholder approach. Different from the existing literature that elaborated the drivers and the advantages of coordination, this paper aims to explore the coordination mechanism regarding whether to coordinate, when to adopt the optimal coordinated strategy and how such a strategy can perform well. To analyze the tendency of the coordinated decisions, evolutionary game models concerning traditional and trust mechanisms were developed. Then, computational studies based on hypothetic data were simulated to validate the effectiveness of the proposed model. Results indicated that the coordination decision was affected by coordinated returns and costs, normal returns and extra returns in terms of the traditional mechanism. Several situations in regard to the coordinated decisions were analyzed by adopting evolutionary stable strategies. Moreover, trust had a significantly positive impact on coordination promotion under the support of potential returns and high-level trust. Finally, managerial insights for achieving the sustainable humanitarian 
supply chain were given from the perspective of organizational coordination and strategy.

Keywords: Sustainable humanitarian supply chain; stakeholder approach; coordination mechanism; private sector; trust; evolutionary game model

\section{Introduction}

It is reported that an increasing number of disasters have led to overwhelming losses in recent years. For instance, large-scale disasters approximately caused property losses of 986,691 million dollars and 1,105,352 casualties (Galindo and Batta, 2013). To save lives, decrease human suffering and contribute to development, the philosophies of sustainable development organically being integrated into disaster risk reduction during disaster prevention, mitigation, preparedness and relief need to be identified and recognized, which was portrayed by the UN in 2015 (United Nations, 2015). Similarly, the combination of sustainable development and disaster management was also suggested by Stenson (2006). In addition to that, Van Wassenhove (2006) mentioned that 80 percent of humanitarian aids were related to logistic activities, and inadequate supplies of reliefs or services would result in a bad reaction in the context of disaster. Thus, it can be inferred that investigation on both sustainable humanitarian supply chain (SHSC) and disaster relief supply chain requires urgent attention. Such a viewpoint was also supported by Cao et al. (2018), Cao et al. (2017), Dubey and Gunasekaran (2016) and Haavisto and Kovacs (2014).

According to Cao et al. (2018) and Cao et al. (2017), SHSC can be defined as the integration of humanitarian supply chain (HSC) and sustainable development. On the one hand, an effective performance of traditional HSC can be regarded as a sustainable expectation. In detail, saving lives and decreasing human suffering are consistent with social responsibility, while contributing to development is closely associated with the longer term of sustainability (Haavisto and Kovacs, 2014). On the other hand, triple bottom line (TBL) as a popular method is used to analyze the trade-off among economic, environmental and social aspects in humanitarian logistics (Laguna-Salvadó et al., 2018; Cao et al., 2018; Kunz and Gold, 2015; Vega-Mejia et al., 2017). For example, Cao et al. (2017) employed emergency costs, carbon emissions and the weighted completion times to measure economic, environmental and social dimension of the sustainability. Similarly, the aspects of economy (e.g. effectiveness, efficiency and equity), environment (e.g. pollution reduction and resource conservation) and society (e.g. labor condition and local empowerment) were also considered in the design of a multi-criteria master 
planning decision support system (Laguna-Salvadó et al., 2018). The aforementioned literatures mainly focus on the optimization of various performance objectives, but ignore the importance of several stakeholders. Humanitarian logistics include lots of stakeholders, such as military, humanitarian organization (HO), private sector (PS), non-profit organization (Balcik et al., 2010). And it is almost impossible for a single stakeholder to fulfill the needs of the affected people and infrastructure rebuilding (Akhtar et al., 2012). Further, the achievement of sustainable performance relies on information transparency, enhanced communication and trust, which results from the coordinated supply chain design (Kunz and Gold, 2015). In this context, it is necessary to adopt an effective way (e.g. stakeholder approach) to improve the sustainability of HSC from the viewpoint of organizational coordination.

Given the complexity of business environment and the participation of various stakeholders, the directors of a firm should take into account various stakeholder groups instead of merely focusing on the interests/expectations of themselves. In this circumstance, stakeholder approach is devised to manage the independence among serval stakeholders by balancing different interests/expectations (Freeman, 1984). Specifically, identification of stakeholders, analysis of their interests/expectations and the relationship management are the main works. Not surprisingly, since many organizations as various stakeholders participate in SHSC management, organizational coordination problem can be regarded as a new application of stakeholder approach. For example, various stakeholders (e.g. military, HOs, donors, PSs) are identified in humanitarian logistics (Balcik et al., 2010). As a core stakeholder of SHSC, HO needs to coordinate with other actors by well understanding different interests/expectations of them (Bealt et al., 2016). After reviewing the related works (Numala et al., 2017; Van Wassenhove, 2006; Akhtar et al., 2012; Tatham and Kovacs, 2010; Moshtari, 2016), Dubey and Altay (2018) portrayed that such interests/expectations could be divided into two groups including the resource-based view and the relationship theory. The former uses resources (tangible and intangible) and capacities to explain the drivers of coordination (Akhtar et al., 2012), while the latter emphasizes the important role of relationship (e.g. swift trust and commitment) on coordination (Tatham and Kovacs, 2010; Moshtari, 2016). Although the aforementioned studies explicitly conclude their interests/expectations, the coordination mechanism to balance different interests and expectations is still limited (Altay and Green, 2006; Nurmala et al., 2017). For example, Balcik et al. (2010) adopted the method stemming from commercial supply chain to 
promote HSC coordination in a qualitative way. More specifically, the coordination decision is made by decision makers based on the evaluation of relevant costs (e.g. coordination cost, operational risk cost and opportunistic cost). Such a decision cannot answer when to coordinate and how to perform well, although it is adopted to guide managers whether to coordinate. Moreover, as Balcik et al. (2010) held, the relevant costs should be adjusted by the level of interdependence among supply chain members and the uncertainty of demand and supply (Xu and Beamon, 2006), which requires a perfect rationality of decision makers in a one-stage game. However, due to the asymmetric information, shortsightedness and self-interest, decision makers may show the bounded rationality in multistage games (Shi et al., 2018), especially during disaster operations management (Du and Qian, 2016). To solve this problem, game theory is an effective quantitative method to explore the strategic behavior between at least two players, when the two players' interests are in conflict, and their actions are interactive $(\mathrm{Xu}$ and Beamon, 2006). Besides, compared with classic game theory, evolutionary game model (EGM) highlights the importance of the bounded rationality and dynamic evolutionary of strategy. It provides an effective approach to analyze the coordinated tendency of multi-suppliers (Yu et al., 2009). As such, how to formulate the coordinated game as an EGM to answer whether to coordinate, when to select an optimal coordination decision and how to perform well is the purpose of this paper.

Although lots of literature discuss the HSC/SHSC coordination from different perspectives, few researchers concentrate on how this model evolves as the implementation progress in a quantitative way. The purpose of this paper is to investigate the evolutionary process of the coordinated game through the help of the EGM. The other contributions can be concluded from the following three aspects. Firstly, PS-HO partnership is the main focus of this paper, and the importance of such a partnership is summarized as follows. On the one hand, coordination has a positive impact on their performance improvement (Van Wassenhove, 2006; Nurmala et al., 2017). In detail, for HO, since PS has a rich resource to manage materials, service information and capital flow, it usually acts as a significant logistics service provider in humanitarian aids (Schulz and Blecken, 2010). And the participation of PSs determines the difference between successful or failed disaster operations (Van Wassenhove, 2006). For PS, humanitarian relief can be regarded as a multi-billion-dollar market, which draws PS to take part in humanitarian logistics. In addition to that the coordination is also motivated by non-economic benefits (e.g. brand images, corporate social responsibility and staff motivation) (Balcik et al., 2010). On the 
122 other hand, as Nurmala et al. (2017) pointed out, although the benefits were obvious, such coordination seemed uncommon because of the conflicting interests (e.g. PS concentrates on

124 profit-making while $\mathrm{HO}$ aims to save lives, decrease suffering and contribute to development).

125 Consequently, it is pressing to design an optimal mechanism to manage their partnership, which is also identified as a research gap in the study of Nurmala et al. (2017). Secondly, to explore different interests of $\mathrm{HO}$ and PS, performance management (e.g. normal returns, coordinated returns, extra returns and coordinated costs) (Akhtar et al., 2012) and trust behavior (Lu et al., 2018; Dubey et al., 2017) are simultaneously considered to manage the independence between them. Specifically, the traditional mechanism tends to test the value of coordination from the perspective of performance management. The trust mechanism aims to promote coordination from the viewpoint of relationship management (Dubey and Altay, 2018). Such two mechanisms provide decision tools to decide whether to coordinate, when to coordinate and how to adopt an optimal strategy. Thirdly, this paper is to not only validate the designed methodology regarding organizational coordination problem and improve the performance of SHSC, but call for the urge of integrating philosophies of sustainable principle (e.g. stakeholder approach) into the design of the organizational coordination mechanism in humanitarian logistics.

The rest of this paper is organized as follows: Section 2 presents a critical literature review. In Section 3 and Section 4, the EGM concerning organizational coordination problems is proposed. Then, necessary analysis is also presented. Computational studies are implemented in Section 5. Discussion and managerial insights are also summarized. Finally, conclusions and future directions are given in Section 6.

\section{Literature review}

To save lives, decrease human suffering and contribute to development, SHSC and organizational coordination have received considerable attention. In line with the title and structure of this paper, three aspects are reviewed as follows: (1) the relationship between organizational coordination and SHSC, evolutionary game theory.

\subsection{Relationship between organizational coordination and SHSC}

The total number of natural disasters has shown a growing trend in recent years. To deal with the huge challenge of humanitarian logistics pressure, the attention to SHSC increases 
management, there are very few publications to elaborate the importance of coordination in SHSC. Therefore, the related studies are extended to the HSC.

On the one hand, the main performance measurement of HSC focuses on time saving and cost efficiency (Haavisto and Kovacs, 2014), and it is verified that organizational coordination has a positive impact on improving such performances. For example, Balcik et al. (2010) portrayed that a quick response required a coordinated effort. If not, the suffering of the affected population may be prolonged because of the poor management of coordination (Moshtari, 2016). Similarly, Nolte and Boenigk (2011) argued that an enforced organizational structure was helpful for time saving and quality improvement of relief. However, as Brown et al. (2011) examined, due to the conflicting cultures and interests, coordination played a negative role in performance improvement of HSC, especially among temporary organizations. Although sustainability is not clearly clarified in the field of HSC management, the objectives (e.g. saving lives, decreasing human suffering and contributing to development) are still consistent with the goal of sustainable development (Haavisto and Kovacs, 2014).

On the other hand, coordination is also regarded as a critical issue in the field of SHSC management (Kunz and Gold, 2015), although the motivations, methods and objectives are extremely different between HSC and SHSC (Cao et al., 2018). For example, Dubey and Gunasekaran (2016) identified that the sustainability of HSC (e.g. agility, adaptability and alignment) relied on an enforced coordination network. Kapucu et al. (2013) argued that continuous operation was the critical feature of the sustainability, and it could be fulfilled by an optimal coordination network. Meanwhile, Cao et al. (2017) suggested that the sustainability of HSC (e.g. economic, environmental and social aspects) could be achieved by the optimization of organization allocation. Not surprisingly, there is not always positive impact of coordination on performance improvement. For example, Large and Thomsen (2011) found that environmental coordination had a negative impact on purchasing performance. Moreover, the results of Gimenez et al. (2012) only provided partial support for the positive impact of coordination on the TBL achievement.

In summary, the positive impact of coordination is widely accepted as the main idea by lots of researchers as a result of resource complementation (Moshtari, 2016), risk sharing (Akhtar et al., 2012) and coherence of actions (Dubey and Altay, 2018). On the contrary, the opposite viewpoint is also contended because of the conflicting interests, cultures and agendas (Van 
Wassenhove, 2006; Brown et al. 2011; Large and Thomsen, 2011), although the importance of coordination is not completely denied in their studies. Indeed, such conflicts challenge the effectiveness of coordination, especially in disaster practical operations management. Fortunately, such a challenge can be solved by the optimal managerial approaches/theories in terms of information sharing, performance management, cultural cohesion and relationship management (Dubey and Altay, 2018). Consequently, in this paper, it is assumed that coordination plays a positive role in performance improvement of SHSC, and the related issue of organizational coordination is reviewed in next subsection.

\subsection{Organizational coordination issue}

Coordination has been recognized as one of the critical factors to affect successful disaster operations management by many researchers and disaster managers, especially between PS and HO (Van Wassenhove, 2006; Balcik et al., 2010; Nurmala et al., 2017). Motivated by the positive impact of coordination on both HSC and SHSC management, the coordination mechanism regarding how to manage the independence among organizations is of great significant (Balcik et al., 2010). To explicitly analyze the mechanism, different interests and expectations of organizational coordination should be clarified here. After widely reviewing literature, the interests and expectations of organizations can be concluded as the drivers of coordination in the process of coordination. Specially, Dubey and Altay (2018) classified various drivers of coordination into the resource-based viewpoint (e.g. information sharing, visibility and performance management) and the relationship perspective (e.g. swift trust, commitment and culture cohesion).

On the one hand, different interests (e.g. PS dedicates to stock market, high revenues and profits while HO prefers to save live and decrease human suffering) are identified as a critical challenge for coordination promotion between PS and HO (Van Wassenhove, 2006). Thus, performance management is highlighted here. For PS, the purpose of performance management is cost reduction (e.g. inventory cost, transportation cost, customization cost) and profit maximization (e.g. high turnover rate and a large number of deterministic orders) (Nurmala et al., 2017). However, given the preferences of procuring locally, the uncertainty of disaster, and the levels of funding, $\mathrm{HO}$ usually requests for inventory pre-positioning and competitive bidding (Balcik et al., 2010), which greatly increases the cost of PS. To effectively manage the relationship, Balcik et al. (2010) employed coordination cost, opportunistic cost and operational 
risk cost to measure the coordination in terms of procurement, warehousing and transportation management. Particularly, the attributes of commercial supply chain coordination mechanism (e.g. resource sharing structure, level of control, risk/reward sharing and decision style) were replaced by quick response, continuous replenishment and coordinated procurement. Such a mechanism was also applied in Akhtar et al. (2012).

On the other hand, coordination promotion is also discussed from the perspective of relationship management, although performance management viewpoint is helpful to manage the coordination well. For example, Dubey et al. (2017) identified that swift trust was a missing links for HSC coordination. Similarly, Kapucu et al. (2013) verified that inter-organizational trust was the most significant factor in coordination promotion. Therefore, to integrate trust behavior into the coordination mechanism, Tatham and Kovacs (2010) analyzed different levels of trust in coordination promotion and performance improvement. In detail, the strength of trust depends on five routes (e.g. rule, third-party information, category, role and dispositional trust).

Overall, both performance management and relationship management are well applied to the design of coordination mechanism, but few authors simultaneously address the two aspects. As Dubey and Altay (2018) identified, there was a transitive link between performance management and relationship management. In other words, the relationship management can be regarded as a supplementary factor of the performance management, which plays a critical role in coordination management. Therefore, in this paper, the integrated mechanism is devised based on such two aspects.

\subsection{Evolutionary game theory and its applications}

Game theory was widely applied to model the social interaction and provide an effective decision-making guideline for game players. In order to obtain a great prediction of players' strategy, the classic game theory assumes that players show perfect rational behaviors (e.g. acknowledge actions and characteristics of all the other players), although it is impossible for each player to be acquainted with the information of others (Chen et al., 2018). To address the issue mentioned above, the EGM highlighted the importance of replicator dynamics when players with bounded rationality would adjust their strategies in light of their previous actions, especially the successful strategy. Replicator dynamics is denoted by the differential equation in the EGM, so as to describe the dynamic frequency change of the discrete decision in evolutionary games (subsection 3.3 for more details). According to Cai and Kock (2009), such a 
method leverages and extends the ideas of the classic game theory.

According to Yu et al. (2009), EGM is widely applied to study the social interaction in the field of economics and sociology, especially to manage supply chain coordination (Seuring, 2013). To our knowledge, the application of MS/OR method (e.g. EGM) is unsound in the field of HSC. Given the similarity between HSC and commercial supply chain, the boundary of our review is expanded to the field of commercial supply chain. For example, Shi et al. (2018) proposed a game model with the concern of product prices and its costs, incentive returns, spillover effect as well as coordinated costs, so as to investigate the cooperative relationship among construction suppliers. To achieve the integration of the entire supply chain, Yu et al. (2009) developed an EGM, and the model was captured by normal benefits (traditional strategy), new benefits (VMI strategy), penalties and investment. Similarly, a cooperation strategy was also designed as an EGM to enhance the sustainability of two competing suppliers (Xie, 2016). In literature of HSC, a few researchers did the similar work to promote coordination. For example, Du and Qian (2016) characterized normal returns, coordinated benefits and costs, rewards, penalties as well as the value of legitimacy as an EGM to describe the relationship between governments and nonprofit organizations, and it aims to promote collaboration during the period of disaster mobilization. Liu and Xie (2016) analyzed the prices and costs of relief, overtime pay as well as the possibility of successful transaction on emergency supply requisition negotiation.

In summary, compared with classic game theory, EGM is an effective method to manage the relationship among organizations, especially in the context of time pressure and information asymmetry. In this paper, the related factors (e.g. performance management and trust behavior) are treated as the returns and costs, and the questions regarding when to coordinate and how to perform well can be solved by the results of EGM.

\section{The game model concerning the traditional mechanism}

In this section, the behavior of organizations in SHSC coordination are formulated as a decision-making game. Specially, the traditional mechanism concerning performance management is firstly discussed here.

\subsection{Problem description}

In this subsection, a two-tier supply chain structure consisting of demand points with multiple HOs and external suppliers with lots of PSs is considered. One actor is randomly selected from demand points and external suppliers each time to carry out the coordinated game. 
Both PSs and HOs decide whether to coordinate with others. Particularly, for PS, whether to provide philanthropic help (e.g. cash-based donation and strategic help) is the main difference between coordination and non-coordination strategy (Van Wassenhove, 2006; Balcik et al., 2010).

The unobservable system is the highlight of this paper. HOs fail to know if PSs adopt coordination strategy, and if they can get more profits when they coordinate with PSs. Meanwhile, PSs also don't know any information mentioned onwards. Thus, a dynamic game exists in the interaction between PSs and HOs. In other words, since both PSs and HOs are bounded rationality, the coordinated decision is closely related to their previous behaviors.

With regard to PSs, normal returns, coordinated returns and extra returns are the main benefits when they interact with HOs. When PSs only act as a tool/operator (e.g. choose the non-coordinate strategy) in humanitarian logistics, normal returns can be gained from the commercial transaction (Balcik et al., 2010; Vega and Roussat, 2015). Besides, opportunistic behaviors (e.g. shrinking responsibilities, providing low-quality relief and delaying delivery) (Xu and Beamon, 2006) and "free rider" problems (Yu et al., 2009) may exist. They will obtain extra returns from the aforementioned behaviors. On the contrary, a few PSs desire to coordinate, and they will establish a philanthropic relationship with HOs. After that, more economic benefits and non-economic benefits (e.g. brand images, corporate social responsibilities and staff motivation) are gained as the coordinated returns of PSs (Balcik et al., 2010). Absolutely, necessary costs should also be paid for their interaction. In order to maximize their returns, it is challenging for PSs to balance the returns and costs.

In terms of HOs, normal returns, coordinated returns, extra returns are also important. The decision process is similar to that of PSs, and it also aims to maximize their returns in coordination games. However, due to the non-profit characteristic of HOs, it is necessary to illustrate the returns and costs of HOs. As Nurmala et al. (2017) argued, HOs concentrated on performance improvement regarding quick response, time saving and continuous replenishment (details see Table. 1). Such an improvement can be treated as financial returns by adopting some methods, such as key performance indicators (Blecken et al., 2009). For example, the efficiency of disaster response was treated as financial returns in their model ( $\mathrm{Du}$ and Qian, 2016). Chen and Sun (2017) did a similar work to stand for performance improvement. 


\begin{tabular}{|c|c|c|}
\hline \multirow{2}{*}{$\begin{array}{l}\text { Item(s) } \\
\text { Returns and costs }\end{array}$} & \multicolumn{2}{|c|}{ Performance measurement } \\
\hline & for $P S$ & for $\mathrm{HO}$ \\
\hline Normal returns & $\begin{array}{l}\text { A multi-billion-dollar market (Balcik } \\
\text { et al., 2010) }\end{array}$ & $\begin{array}{l}\text { Rapid and stable relief supply, high } \\
\text { quality of product/service (Nurmala et } \\
\text { al., 2017) }\end{array}$ \\
\hline Coordinated returns & $\begin{array}{l}\text { 1. Direct economic returns, search } \\
\text { for new ways for expanding their } \\
\text { agility capacities (Beamon and } \\
\text { Balcik, 2008); } \\
\text { 2. Non-economic returns (e.g. brand } \\
\text { image, staff motivation, corporate } \\
\text { social responsibility, mitigate the } \\
\text { negative impact of disasters on } \\
\text { business sustainability (Rueede and } \\
\text { Kreutzer, 2014; Moan et al. 2009; } \\
\text { Van Wassenhove, 2006). }\end{array}$ & $\begin{array}{l}\text { 1. Cash-based donation, strategic-based } \\
\text { help (Balcik et al., 2010); } \\
\text { 2. Achieving a more accountable, visible } \\
\text { and effective performance by learning } \\
\text { the experience of commercial supply } \\
\text { chain management (Oloruntoba and } \\
\text { Gray, 2009); } \\
\text { 3. Reducing the risk of relief shortage, } \\
\text { improving the capacity of continuous } \\
\text { replenishment (Nurmala et al., 2017; } \\
\text { Balcik et al., 2010). }\end{array}$ \\
\hline Extra returns & $\begin{array}{l}\text { 1. Opportunistic behaviors, such as } \\
\text { provide low-quality products, shirk } \\
\text { responsibilities and delay in delivery } \\
\text { (Xu and Beamon, 2006); } \\
\text { 2. "Free rider" problem, which can } \\
\text { be explained as spillover returns } \\
\text { from player's defection (Yu et al., } \\
\text { 2009). }\end{array}$ & $\begin{array}{l}\text { 1. Opportunistic behavior, such as unfair } \\
\text { price-based competitive bidding, shirks } \\
\text { responsibilities and contract broken } \\
\text { (Balcik et al., 2010); } \\
\text { 2. "Free rider" problem, and it is similar } \\
\text { to PS, especially HO with bureaucracy. }\end{array}$ \\
\hline Coordinated costs & $\begin{array}{l}\text { 1. Philanthropic help (e.g. strategic } \\
\text { help and donation (Balcik et al., } \\
\text { 2010); } \\
\text { 2. Interaction behavior (e.g. manage } \\
\text { information, award the contract and } \\
\text { attend meeting) (Balcik et al., 2010); } \\
\text { 3. Rapid relief supply (e.g. staff } \\
\text { salaries, inventory pre-positioning } \\
\text { management) (Balcik et al., 2010). }\end{array}$ & $\begin{array}{l}\text { Interactive behavior (e.g. acknowledge } \\
\text { HO's culture, method and agenda, attend } \\
\text { coordination meeting, award a contract } \\
\text { (Balcik et al., 2010). }\end{array}$ \\
\hline
\end{tabular}

\subsection{Model formulation}

To present a comprehensive overview of various factors, the following parameters (Table. 2) are summarized here. 


\begin{tabular}{|c|c|c|}
\hline Item & Parameter & Description \\
\hline \multirow{5}{*}{ for $P S$} & $x$ & $\begin{array}{l}\text { The possibility of coordination strategy adopted by PSs. On the contrary, } 1-x \text { denotes the } \\
\text { possibility of adoption regarding non-coordination strategy; }\end{array}$ \\
\hline & $R_{p}$ & $\begin{array}{l}\text { Normal returns obtained from the absolute commercial relationships (no one adopts the } \\
\text { coordination strategy); }\end{array}$ \\
\hline & $\alpha_{1}$ & $\begin{array}{l}\text { Ratio of increased returns of the mutual coordination to normal returns (both PSs and HOs } \\
\text { adopt the coordination strategy); }\end{array}$ \\
\hline & $\alpha_{2}$ & $\begin{array}{l}\text { Ratio of increased returns of the unfair coordination to normal returns (only PS desires to } \\
\text { coordinate with } \mathrm{HO} \text { ); }\end{array}$ \\
\hline & $C_{p}$ & The coordinated costs should be paid by PSs when they choose the coordination strategy; \\
\hline & $\pi_{p}$ & Extra returns obtained by PSs due to the opportunistic behavior and the "free rider" problem. \\
\hline \multirow{6}{*}{ for $\mathrm{HO}$} & $y$ & $\begin{array}{l}\text { The possibility of coordination strategy adopted by HOs. On the contrary, 1-y denotes the } \\
\text { possibility of non-coordination strategy; }\end{array}$ \\
\hline & $R_{h}$ & $\begin{array}{l}\text { Normal returns obtained from the absolute commercial relationship (no one adopts the } \\
\text { coordination strategy); }\end{array}$ \\
\hline & $\beta_{1}$ & $\begin{array}{l}\text { Ratio of increased returns of the mutual collaboration to normal returns (both PSs and HOs } \\
\text { adopt the coordination strategy); }\end{array}$ \\
\hline & $\beta_{2}$ & $\begin{array}{l}\text { Ratio of increased returns of the unfair coordination to normal returns (only } \mathrm{HO} \text { desires to } \\
\text { coordinate with PS); }\end{array}$ \\
\hline & $C_{h}$ & Coordinated costs should be paid by HOs when they choose the coordination strategy; \\
\hline & $\pi_{h}$ & Extra returns obtained by HOs due to the opportunistic behavior and the "free rider" problem. \\
\hline
\end{tabular}
strategy. Four coordinated modes (Fig. 1) are developed from the cross tabulation of such

314 strategies. Moreover, it was identified that mutual collaboration was the most effective way to achieve the sustainability of SHSC (Dubey and Gunasekaran, 2016).

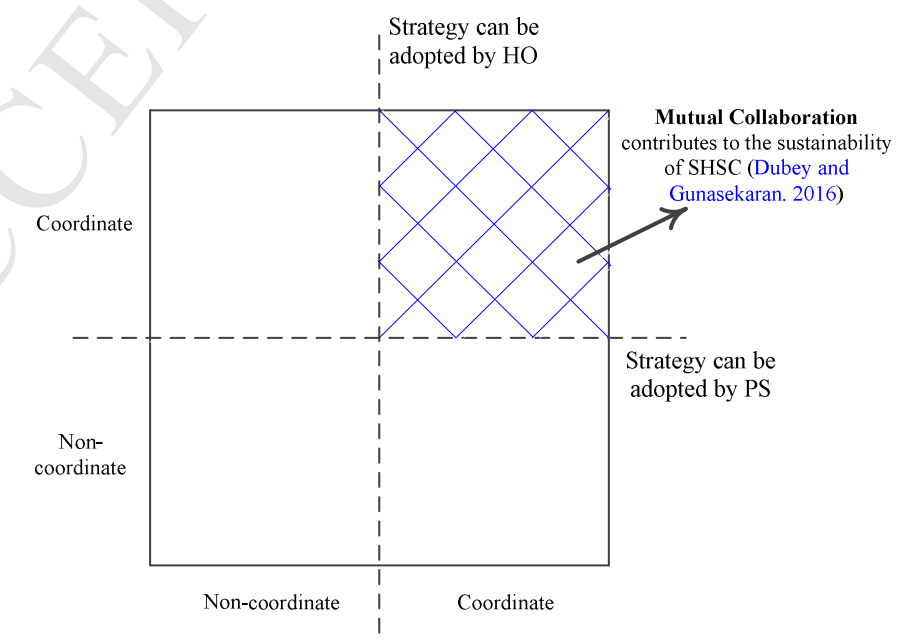


To propose the EGM, four coordinated modes are discussed here. In this model, both PSs and HOs tend to maximize their returns when they choose the coordinated strategy.

(1) Case 1: \{non-coordinate, non-coordinate $\}$. No one adopts coordination strategy, and an absolutely commercial relationship is established (Balcik et al., 2010). Both PSs and HOs can only obtain normal returns $R_{p}$ and $R_{h}$ (Vega and Roussat, 2015), and $R_{p}>0, R_{h}>0$ respectively;

(2) Case 2: \{coordinate, coordinate $\}$. An optimal strategy regarding mutual collaboration is profits) and non-economic returns (e.g. staff motivation, brand image and corporate social responsibilities) can be earned (Van Wassenhove, 2006; Balcik et al., 2010), and it is denoted by $\left(1+\alpha_{1}\right) R_{p}$. To obtain such returns, necessary costs $C_{p}$ (see Table. 1$)$ should be paid. For HOs, the coordinated returns (e.g. extra cash-based donation and strategic help) can be obtained because of their coordination behavior (Nurmala et al., 2017). Such returns can be represented by $\left(1+\beta_{1}\right) R_{h}$. Similarly, HOs also should put $C_{h}$ to the common pool.

(3) Case 3: \{non-coordinate, coordinate $\}$. The unfair coordination that only the HO prefers to coordinate exists in this game. In this context, HOs can also obtain some coordinated returns $\left(1+\beta_{2}\right) R_{h}$, although such returns are less than $\left(1+\beta_{1}\right) R_{h}$. What leads to such a phenomenon is that mutual collaboration is the best situation to improve the whole performance of the coordinated system (both PSs and HOs), and it was validated by Dubey and Gunasekaran (2016). Besides, the coordinated costs $C_{h}$ should be paid by HOs. With regard to PSs, extra returns $\pi_{p}$ can be obtained from opportunistic behavior (see Table. 1) and "free rider" problems as a result of adoption of the defection strategy (Xu and Beamon, 2006; Yu et al., 2009).

(4) Case 4: $\{$ coordinate, non-coordinate $\}$. As an opposite case compared with case 3, coordination strategy is only adopted by PSs. $\pi_{h}+R_{h}$ and $\left(1+\alpha_{2}\right) R_{p}-C_{p}$ stand for their returns.

According to the aforementioned statements, the return matrix is shown in Table. 3. 


\begin{tabular}{cccc}
\hline & & \multicolumn{2}{c}{ Humanitarian Organization (HO) } \\
\cline { 2 - 4 } & & Coordinate $(y)$ & Non-coordinate $(1-y)$ \\
\hline \multirow{2}{*}{$\begin{array}{c}\text { Private Sector } \\
\text { (PS) }\end{array}$} & Coordinate $(x)$ & $\left(1+\alpha_{1}\right) R_{p}-C_{p} ;$ & $\left(1+\alpha_{2}\right) R_{p}-C_{p} ;$ \\
& & $\left(1+\beta_{1}\right) R_{h}-C_{h}$ & $\pi_{h}+R_{h}$ \\
& Non-coordinate $(1-x)$ & $\pi_{p}+R_{p} ;$ & $R_{p} ;$ \\
\hline
\end{tabular}

\subsection{The replicator dynamics system and equilibrium points}

Based on Table. 3, the expected returns of PSs that adopt coordination strategy are:

$$
E_{x}=y\left[\left(1+\alpha_{1}\right) R_{p}-C_{p}\right]+(1-y)\left[\left(1+\alpha_{2}\right) R_{p}-C_{p}\right]
$$

The expected returns of PSs that don't adopt coordination strategy are:

$$
E_{1-x}=y\left(\pi_{p}+R_{p}\right)+(1-y) R_{p}
$$

The average expected returns of PSs under the mixed strategies can be denoted by:

$$
\overline{E_{x(1-x)}}=x E_{x}+(1-x) E_{1-x}=\left[\left(\alpha_{1}-\alpha_{2}\right) R_{p}-\pi_{p}\right] x y+\left(\alpha_{2} R_{p}-C_{p}\right) x+\pi_{p} y+R_{p}
$$

Based on the EGM, the expected returns of a strategy selected by one player are higher than the average expected returns of the population, and the strategy will spread in the population (Chen et al., 2018). Thus, the replicator dynamics system denoted by the differential equation can be used to describe the frequency of such strategies.

$$
\frac{d x}{d t}=x\left(E_{x}-\overline{E_{x(1-x)}}\right)=x(1-x)\left\{\left(\alpha_{2} R_{p}-C_{p}\right)-\left[\pi_{p}-\left(\alpha_{1}-\alpha_{2}\right) R_{p}\right] y\right\}
$$

Similarly, the replicator dynamics system of HOs is presented by:

$$
\frac{d y}{d t}=y\left(E_{y}-\overline{E_{y(1-y)}}\right)=y(1-y)\left\{\left(\beta_{2} R_{h}-C_{h}\right)-\left[\pi_{h}-\left(\beta_{1}-\beta_{2}\right) R_{h}\right] x\right\}
$$

Based on Eq. (4) and (5), five equilibrium points, namely $(0,0),(1,0),(0,1),(1,1)$ and $\left(x^{*}, y^{*}\right)$, where:

$$
x^{*}=\frac{\beta_{2} R_{h}-C_{h}}{\pi_{h}-\left(\beta_{1}-\beta_{2}\right) R_{h}} ; \quad y^{*}=\frac{\alpha_{2} R_{p}-C_{p}}{\pi_{p}-\left(\alpha_{1}-\alpha_{2}\right) R_{p}}
$$

As Friedman (1991) pointed out, the Jacobian matrix of the replicator dynamics system is defined by Eq. (7).

$$
J=\left[\begin{array}{ll}
a_{11} & a_{12} \\
a_{21} & a_{22}
\end{array}\right]
$$

where: 


$$
\begin{aligned}
& a_{11}=(1-2 x)\left\{\left(\alpha_{2} R_{p}-C_{p}\right)-\left[\pi_{p}-\left(\alpha_{1}-\alpha_{2}\right) R_{p}\right] y\right\} \\
& a_{12}=-x(1-x)\left[\pi_{p}-\left(\alpha_{1}-\alpha_{2}\right) R_{p}\right] \\
& a_{21}=-y(1-y)\left[\pi_{h}-\left(\beta_{1}-\beta_{2}\right) R_{h}\right] \\
& a_{22}=(1-2 y)\left\{\left(\beta_{2} R_{h}-C_{h}\right)-\left[\pi_{h}-\left(\beta_{1}-\beta_{2}\right) R_{h}\right] x\right\}
\end{aligned}
$$

The determinant and the trace of the Jacobian matrix are respectively denoted by $\boldsymbol{d e t} \boldsymbol{J}$ and

trJ. They are denoted as:

$$
\operatorname{det} J=a_{11} a_{22}-a_{12} a_{21} ; \quad \operatorname{tr} J=a_{11}+a_{22}
$$

When $\operatorname{det} J>0$ and $\operatorname{tr} J<0$, the equilibrium point of the replicator dynamics system is locally stable, and it is regarded as the evolutionary stable strategy (ESS) in the coordinated game.

\subsection{Evolutionary stable strategies considering different scenarios}

In the light of model analysis, five ESSs are depicted in Fig. 2. Nodes $O, A, B$ and $C$ represent four types of coordinated modes.

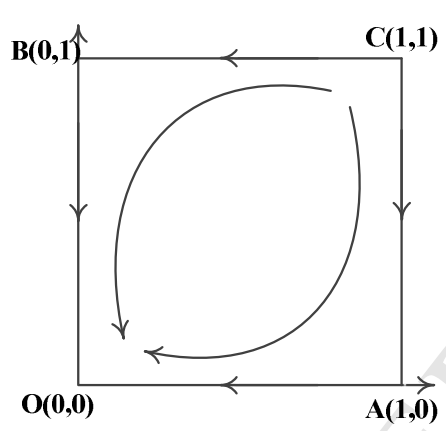

(a) Scenario 1

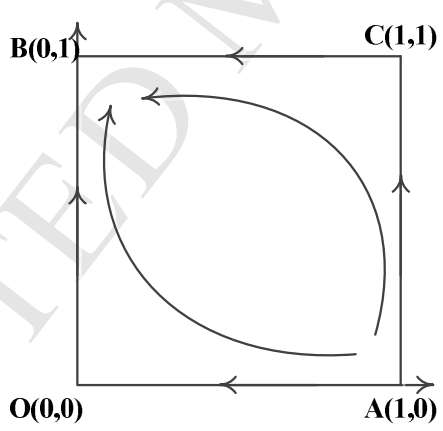

(b) Scenario 2

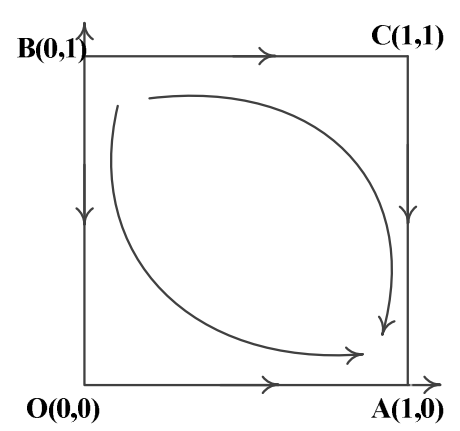

(c) Scenario 3

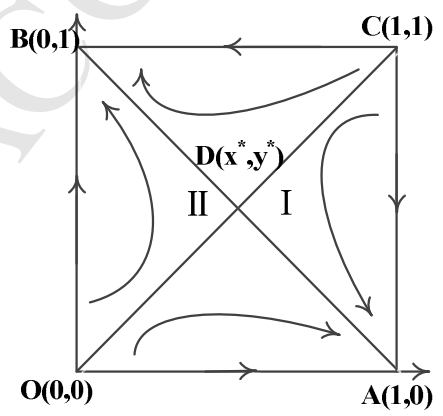

(d) Scenario 4

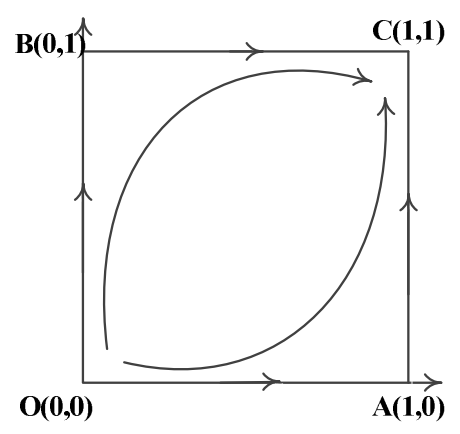

(e) Scenario 5

Fig. 2 Evolutionary stable strategies of the traditional mechanism 
Scenario 1 (Fig. 2a):when $0<\alpha_{2}<C_{p} / R_{p}, \alpha_{2}<\alpha_{1}<\left(C_{p}+\pi_{p}\right) / R_{p}, 0<\beta_{2}<C_{h} / R_{h}$, $\beta_{2}<\beta_{1}<\left(C_{h}+\pi_{h}\right) / R_{h}, O(0,0)$ is the only equilibrium point of the replicator dynamics system, and it means that non-coordination strategy is the optimal strategy for both players. It may result from a small value of $C_{p} / R_{p}$ and $C_{h} / R_{h}$. In other words, the net returns (the difference of the coordinated returns and their costs) obtained from coordination strategy are less than that of non-coordination strategy for each actor.

Scenario 2 (Fig. 2b): when $\alpha_{2}<\alpha_{1}<\left(C_{p}+\pi_{p}\right) / R_{p}, C_{h} / R_{h}<\beta_{2}<\beta_{1}<\left(C_{h}+\pi_{h}\right) / R_{h}$, $0<\alpha_{2}<C_{p} / R_{p}$, the equilibrium point will evolve to $B(0,1)$ after several games. In this scenario, HOs prefer to coordinate due to the great value of net returns $\left(\beta_{2} R_{h}>C_{h}\right)$. On the other hand, inadequate benefits and undesired collaborated costs are found $\left(\alpha_{2} R_{p}<C_{p}\right.$, $\alpha_{1} R_{p}<C_{p}+\pi_{p}$ ) from the coordination of PSs. However, the extra returns $\pi_{p}$ can be obtained from their defection. Hence, non-coordination strategies are adopted by PSs.

Scenario 3 (Fig. 2c): when $C_{p} / R_{p}<\alpha_{2}<\alpha_{1}<\left(C_{p}+\pi_{p}\right) / R_{p}, \quad 0<\beta_{2}<C_{h} / R_{h}$, $\beta_{2}<\beta_{1}<\left(C_{h}+\pi_{h}\right) / R_{h}$, compared with scenario $2, A(1,0)$ is an opposite case, which indicates that an unfair coordination strategy is only adopted by HOs.

Scenario 4:when $C_{p} / R_{p}<\alpha_{2}<\alpha_{1}<\left(C_{p}+\pi_{p}\right) / R_{p}, C_{h} / R_{h}<\beta_{2}<\beta_{1}<\left(C_{h}+\pi_{h}\right) / R_{h}$, an interesting and reasonable situation including two equilibrium points $A(1,0)$ and $B(0,1)$ will exist in the replicator dynamics system (Fig. 2d). In this context, the ESS is uncertain, and it will be discussed next.

Scenario 5 (Fig. 2e): when $\left(C_{p}+\pi_{p}\right) / R_{p}<\alpha_{2}<\alpha_{1}$ and $\left(C_{h}+\pi_{h}\right) / R_{h}<\beta_{2}<\beta_{1}$, an expected state will exist in the coordinated game, which indicates coordination is an optimal strategy for both PSs and HOs. As such, mutual coordination is the best way to achieve the sustainability of HSC, and it was validated by Dubey and Gunasekaran, 2016.

\subsection{Parameter analysis}

As depicted in Fig. 2d, two strategies regarding \{coordinate, non-coordinate\} and \{non-coordinate, coordinate\} are adopted by two players randomly, which is determined by the location of node $D\left(x^{*}, y^{*}\right)$. In other words, the adopted strategy depends on the area of OACD $\left(S_{O A C D}\right)$ and OBCD $\left(S_{O B C D}\right)$. If $S_{O A C D}$ is greater than $S_{O B C D}$, PSs choose the coordination 
strategy, but HOs have an opposite action. To comprehensively test the impact of several factors on their coordinated decision, parameter analysis regarding ratio of increased returns of coordination to normal returns $\left(\alpha_{1}, \alpha_{2}, \beta_{1}\right.$ and $\left.\beta_{2}\right)$, the normal returns $\left(R_{P}\right.$ and $\left.R_{h}\right)$, the coordinated costs $\left(C_{p}\right.$ and $\left.C_{h}\right)$ and the extra returns $\left(\pi_{p}\right.$ and $\left.\pi_{h}\right)$ is implemented. To make a clear statement for readers, necessary proofs are presented in Appendix A. Due to the similar meaning of $S_{O A C D}$ and $S_{O B C D}, S_{O A C D}$ (the possibility of ESS which is captured by coordinate and non-coordination \}) is only discussed here.

Proposition 1: $S_{O A C D}$ will expand with the increased tendency of $\alpha_{1}$ and $\alpha_{2}$, but reduce with the increased tendency of $\beta_{1}$ and $\beta_{2}$. It means returns from coordination (e.g. not only the mutual coordination but also the unfair coordination) positively affect the coordinated decisions. In other words, the motivation for each actor to coordinate can be induced with a strong possibility of coordination returns.

Proposition 2: $S_{O A C D}$ is positively correlated with the normal returns. It means a great value of the normal returns will make a good impression on the opponent, and it attracts each player for interaction.

Proposition 3: The impact of the coordinated costs on $S_{O A C D}$ is commonly negative. Based on transaction cost theory, the coordinated costs (e.g. monitoring cost and necessary investments) will increase the operational risk, which hinders each player from coordinating with anyone $(\mathrm{Xu}$ and Beamon, 2006).

Proposition 4: $S_{O A C D}$ is negatively related to the extra returns. In this context, PSs concentrate on short-term interaction, and they will take some opportunistic behaviors with a high possibility.

\section{The game model concerning the trust mechanism}

Not only performance management but also relationship management (e.g. trust) is the critical motivation of HSC coordination (Dubey and Altay, 2018). Given high uncertainty of disaster contexts, coordination is motivated by trust as a primary principle (Mcevily et al., 2003). Also, Papadopoulos et al. (2017) suggested that swift trust would promote the public-private 
partnership in humanitarian logistics activities. Here, the trust mechanism is designed to accomplish the critical goal.

\subsection{Model formulation}

To design an effective trust mechanism, the relationship between trust and coordination should be elaborated here. As Dubey et al. (2017) and Lu et al. (2018) identified, trust had a great influence on coordination with the help of potential benefits (e.g. information sharing, observed improvement and shared values). The value of potential benefits is determined by the level of trust (Lu et al., 2018). In this context, potential returns are treated as an encouragement for coordinators, but a punishment for defectors. Moreover, it will be added into the EGM proposed in Section 3, so as to further promote PS-HO partnership. Based on the aforementioned statements, let $\lambda_{p}$ and $\lambda_{\mathrm{h}}$ denote the level of trust. Besides, $T_{p}$ and $T_{h}$ stand for potential benefits of PSs and HOs. The return matrix of the coordinated game concerning the trust mechanism is demonstrated in Table. 4.

Table. 4 The return matrix of the game with consideration of trust mechanism

\begin{tabular}{cccc}
\hline & & \multicolumn{2}{c}{ Humanitarian Organization (HO) } \\
\cline { 3 - 4 } & & Collaborate $(y)$ & Non-collaborate $(1-y)$ \\
\hline \multirow{3}{*}{$\begin{array}{c}\text { Private Sector } \\
\text { (PS) }\end{array}$} & Collaborate $(x)$ & $\left(1+\alpha_{1}\right) R_{p}-C_{p} ;$ & $\left(1+\alpha_{2}\right) R_{p}-C_{p}+\lambda_{h} T_{p} ;$ \\
& & $\pi_{p}+R_{p}-\lambda_{h} T_{p} ;$ & $\pi_{h}+R_{h}-\lambda_{p} T_{h}$ \\
& Non-collaborate $(1-x)$ & $\left(1+\beta_{2}\right) R_{h}-C_{h}+\lambda_{p} T_{h}$ & $R_{p} ;$ \\
\hline
\end{tabular}

\subsection{The replicator dynamics system and stability analysis}

Based on Friedman (1991), the replicator dynamics system of PSs is denoted by:

$$
\frac{d x}{d t}=x(1-x)\left\{\left(\alpha_{2} R_{p}-C_{p}+\lambda_{h} T_{p}\right)-\left[\pi_{p}-\left(\alpha_{1}-\alpha_{2}\right) R_{p}\right] y\right\}
$$

The replicator dynamics system of HOs is:

$$
\frac{d y}{d t}=y(1-y)\left\{\left(\beta_{2} R_{h}-C_{h}+\lambda_{p} T_{h}\right)-\left[\pi_{h}-\left(\beta_{1}-\beta_{2}\right) R_{h}\right] x\right\}
$$

Five equilibrium points regarding $(0,0),(1,0),(0,1),(1,1)$ and $\left(x^{*}, y^{*}\right)$ can be obtained, where:

$$
x^{*}=\frac{\alpha_{2} R_{p}-C_{p}+\lambda_{h} T_{p}}{\pi_{p}-\left(\alpha_{1}-\alpha_{2}\right) R_{p}} ; \quad y^{*}=\frac{\beta_{2} R_{h}-C_{h}+\lambda_{p} T_{h}}{\pi_{h}-\left(\beta_{1}-\beta_{2}\right) R_{h}}
$$


As Dubey and Gunasekaran, 2016 pointed out, mutual coordination was the best way to achieve the sustainability of HSC, which indicates the ESS should converge to node $C(1,1)$ in this model. After a detailed analysis, results can be summarized as follows. When $\lambda_{h}>$ $\left(C_{p}+\pi_{p}-\alpha_{1} R_{p}\right) / T_{p}, \lambda_{p}>\left(C_{h}+\pi_{h}-\beta_{1} R_{h}\right) / T_{h}$, node $C(1,1)$ is the only equilibrium point of the coordinated game. It means that trust plays an important role in promoting the PS-HO partnership. The necessary proofs are presented in Appendix B.

\section{Computational studies}

Although the theoretical results have been explicitly analyzed in Section 3 and Section 4, to further validate the proposed model, computational studies based on hypothetical data are analyzed here. The indexes of $h$ and $p$ stand for HOs and PSs respectively. Normal returns from business transaction are represented by $R_{p}$ and $R_{h}$. Besides, they are bounded to $R_{p} \in$ $[200,220], R_{h} \in[200,240]$. The ratio of increased returns of mutual coordination to normal returns is located at interval $[0.59,0.9]\left(\alpha_{1} \in[0.59,0.9]\right)$ and $[0.64,0.9]\left(\beta_{1} \in[0.64,0.9]\right)$.

Meanwhile, that of unfair coordination to normal returns is assumed to be a random number at interval $[0.36,0.5]\left(\alpha_{2} \in[0.36,0.5]\right)$ and $[0.34,0.6]\left(\beta_{2} \in[0.34,0.6]\right)$. Coordinated costs are set to $C_{p} \in[80,100]$ and $C_{h} \in[80,120]$. In addition to that extra returns can be denoted by $\pi_{p} \in[50,80]$ and $\pi_{h} \in[80,100]$.

\subsection{Computational results regarding the traditional mechanism}

In this subsection, the uncertain scenario concerning two ESSs is only discussed here.

Moreover, due to the similar strategy adopted by PSs and HOs, for the sake of briefness, the possibility of \{coordinate, non-coordinate $\}$ strategy is only analyzed here. Fig. 3 indicates the ESSs of scenario 4. The possibility of the coordinated strategy adopted by PS and HO is respectively demonstrated by the lateral and the vertical axis. In this figure, the initial value of each possibility is set to 0.6 and 0.6. After several games, they will adjust their strategies and evolve to equilibrium point $(0,1)$ or $(1,0)$. Five evolutionary paths of the coordinated decisions are displayed as different lines, and it is determined by $\alpha_{1}$ and $\alpha_{2}$. 


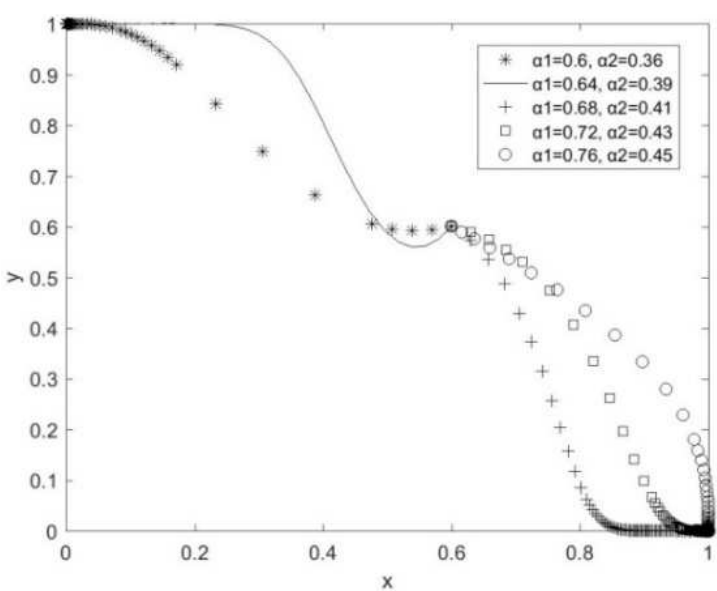

Results indicate that: when other parameter remain unchanged, during the early stage of the coordinated game, non-coordination strategy is the preferred decision adopted by PSs because of

472 the small value of $\alpha_{1}$ and $\alpha_{2}$ (e.g. $\alpha_{1}=0.6$ and $\alpha_{2}=0.36$ ). However, the varying strategy

473 regarding coordination is adopted by PSs due to the increased tendency of $\alpha_{1}$ and $\alpha_{2}$ (e.g. $474 \alpha_{1}=0.72$ and $\left.\alpha_{2}=0.43\right)$. In this context, it can be inferred that coordinated returns have a 475 positive influence on improving the desire of coordination. Such a viewpoint is also supported by 476 Balcik et al. (2010). When PSs coordinate with HOs, both economic benefits and non-economic 477 benefits can be gained from coordination. Thus, such returns with a high value will encourage 478 PSs to participate in humanitarian logistic activities. In order to comprehensively explore how 479 the coordination decision is affected by several factors, parameter analysis is given in next 480 subsection.

\section{$481 \quad 5.2$ Parameter analysis}

482 This subsection aims to investigate the impacts of factors on $S_{O A C D}$ that represents the 483 possibility of evolutionary stable strategy \{coordinate, non-coordinate\} adopted by PSs and HOs 484 respectively.

\section{$485 \quad$ 5.2.1 Ratio of increased returns to normal returns}

The relation among several parameters $\left(\alpha_{1}, \alpha_{2}, \beta_{1}\right.$ and $\left.\beta_{2}\right)$ and $S_{O A C D}$ are exhibited in Fig. 4 respectively. $S_{O A C D}$ is displayed by the vertical axis, while the lateral axis represents the parameters including $\alpha_{1}, \alpha_{2}, \beta_{1}$ and $\beta_{2}$. 


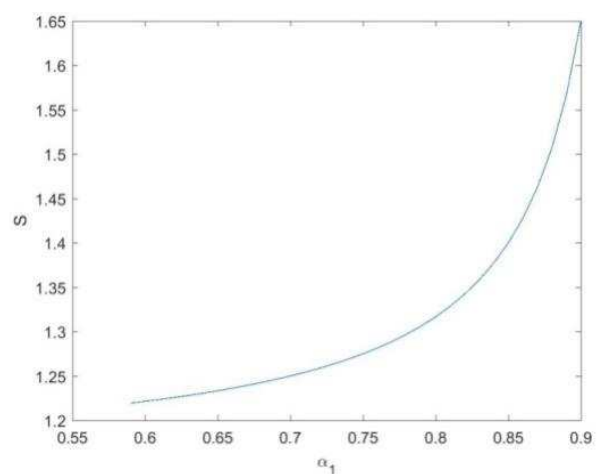

(a). the impact of $\alpha_{1}$ on $S$

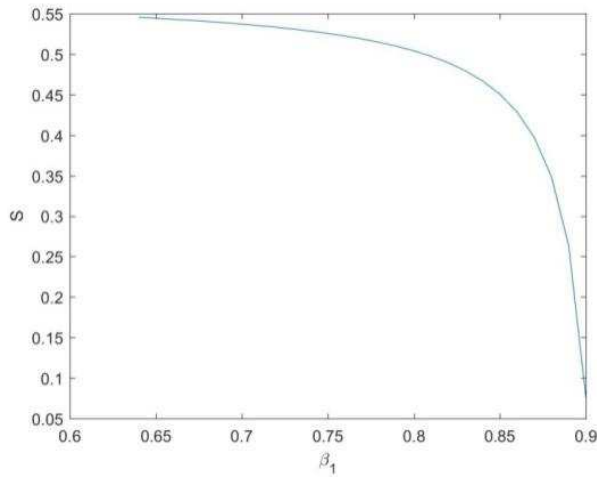

(c). the impact of $\beta_{1}$ on $S$

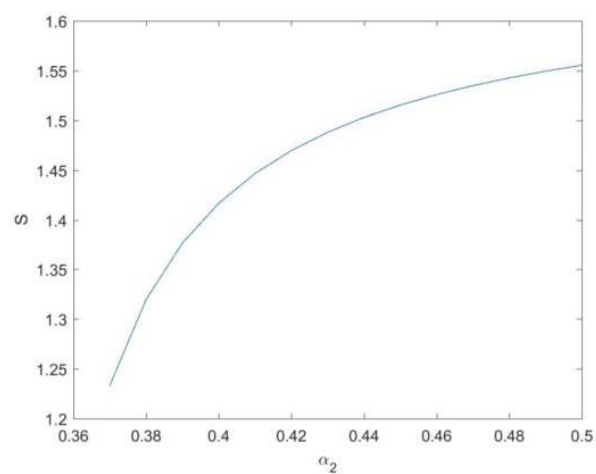

(b). the impact of $\alpha_{2}$ on $S$

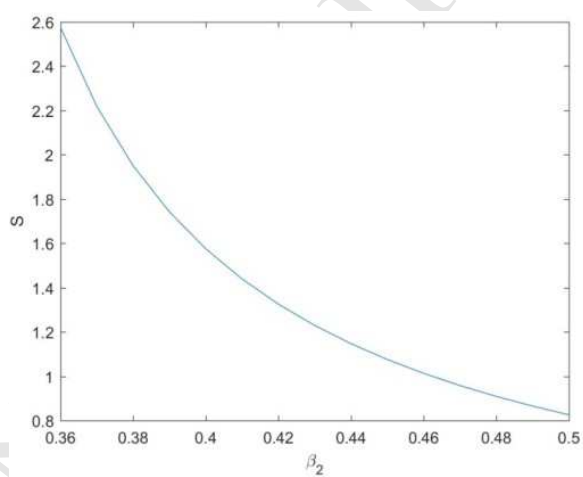

(d). the impact of $\beta_{2}$ on $S$

Fig. 4 Parameter analysis regarding $\alpha_{1}, \alpha_{2}, \beta_{1}$ and $\beta_{2}$

By following Fig. 4, it is reported that $S_{O A C D}$ maintains the ascending tendency for a long time, with an increased $\alpha_{1}$ and $\alpha_{2}$. In contrast, $S_{O A C D}$ decreases as the increased tendency of $\beta_{1}$ and $\beta_{2}$. In this context, the coordinated returns become the essential motivation of PSs or HOs for adopting a coordination strategy, which corresponds to proposition 1 . With regard to PSs, both economic and non-economic benefits obtained from humanitarian logistics activities are the main motivation for coordination (Balcik et al., 2010). Meanwhile, what encourages HOs to coordinate is the performance improvement of humanitarian aid (e.g. time saving, cost efficiency and high quality of products/service) (Van Wassenhove, 2006).

\subsubsection{Normal returns}

The impact of $R_{p}$ and $R_{h}$ (lateral axis) on $S_{O A C D}$ (vertical axis) is shown in Fig. 5. It attempts to explore the relation between normal returns and coordinated strategy. Results demonstrate that: $S_{O A C D}$ is positively affected by $R_{p}$ but negatively influenced by $R_{h}$, which is in line with proposition 2 . 


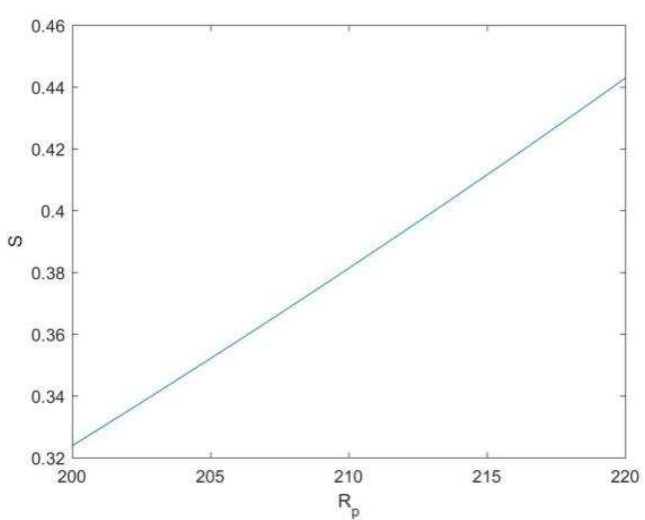

(a). the impact of $R_{p}$ on $S$

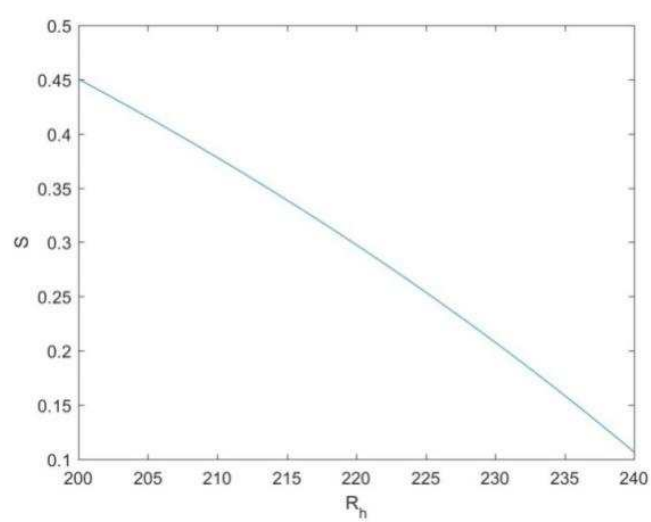

(b). the impact of $R_{h}$ on $S$

Fig. 5 Parameter analysis of normal returns

\subsubsection{Coordinated costs}

Similarly, the relation between coordinated costs (lateral axis) and the possibility of adopting \{collaborate, non-collaborate\} strategy (vertical axis) is depicted in Fig. 6.

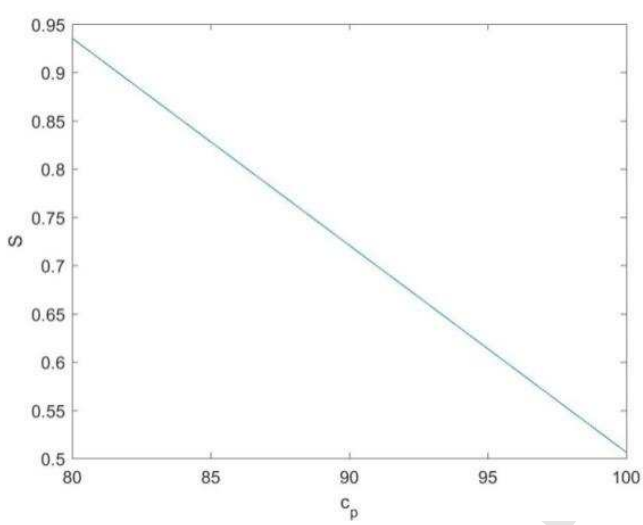

(a). the impact of $C_{p}$ on $S$

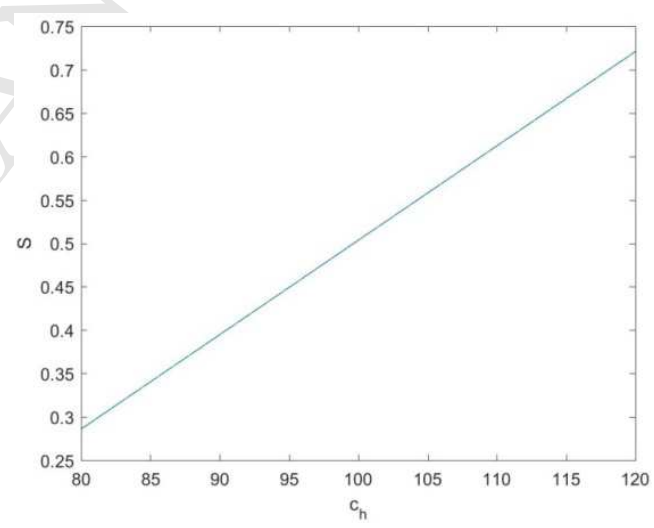

(b). the impact of $C_{h}$ on $S$

Fig. 6 Parameter analysis of coordinated costs

Fig. 6a manifests that $C_{p}$ has a negative influence on $S_{O A C D}$, which corresponds to proposition 3. It denotes that the desire of coordination is declined by PSs because of a high value of coordinated costs. In contrast, Fig. $6 \mathrm{~b}$ shows that $C_{h}$ has a positive impact on $S_{O A C D}$, which points out that the higher coordinated costs aggravate the desire of non-coordination strategy of HOs. As the relationship between PSs and HOs is uncommon in daily life, undesired coordinated costs (e.g. inventory management, contract management and infrastructural investment) should be paid for their partnership, especially in the time-pressure situation. And it 
523 increases the operational risk of HSC (Xu and Beamon, 2006; Balcik et al., 2010).

\subsubsection{Extra returns}

To investigate the impact of extra returns (lateral axis) on their coordinated strategy (vertical axis), the relation between $S_{O A C D}$ and extra returns (e.g. $\pi_{p}$ and $\pi_{h}$ ) is shown in Fig. 7 .

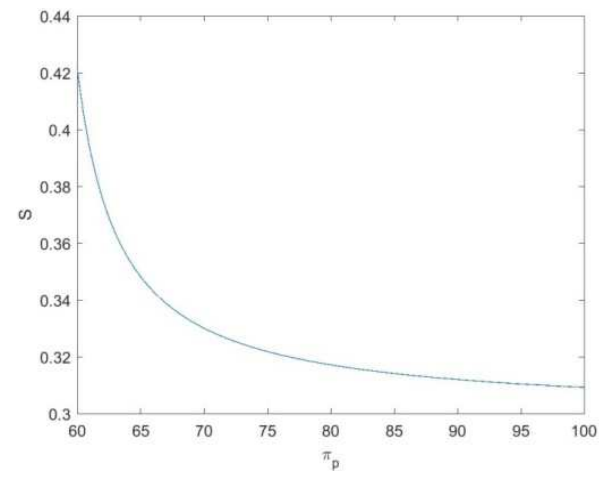

(a). the effect of $\pi_{p}$ on $S$

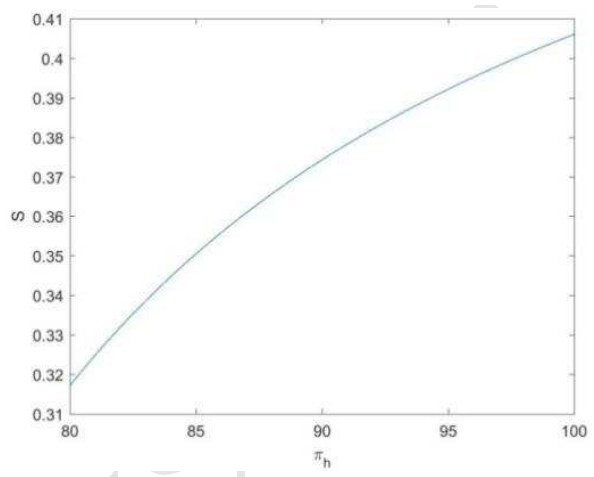

(b). the effect of $\pi_{h}$ on $S$

Fig. 7 Parameter analysis of extra returns

Fig. $7 \mathrm{a}$ and $7 \mathrm{~b}$ indicate that $S_{O A C D}$ is negatively correlated with $\pi_{p}$ but is positively related to $\pi_{h}$, which presents that extra returns have a negative influence on their coordination decision, which is in line with proposition 4.

\subsection{Comparative analysis on traditional and trust mechanisms}

As scenario 4 mentioned in subsection 3.1.4, when $C_{p} / R_{p}<\alpha_{2}<\alpha_{1}<\left(C_{p}+\pi_{p}\right) / R_{p}$, $C_{h} / R_{h}<\beta_{2}<\beta_{1}<\left(C_{h}+\pi_{h}\right) / R_{h}$, a group of opposite situations will alternately appear in the coordinated game, which is based on the first-moved strategy. In order to promote more mutual collaboration between PSs and HOs, the trust mechanism is considered here.

It is reported that trust is an important asset for coordination (Lu et al., 2018). In addition, the level of trust is the main factor affecting the coordinated decisions. In order to comprehensively observe how the coordinated decision is affected by the level of trust $\left(\lambda_{p}\right.$ and $\lambda_{h}$ ), three conditions are discussed in Fig. 8. Specially, the possibility of the coordinated strategy adopted by PS and HO is respectively demonstrated by the lateral and vertical axis. 


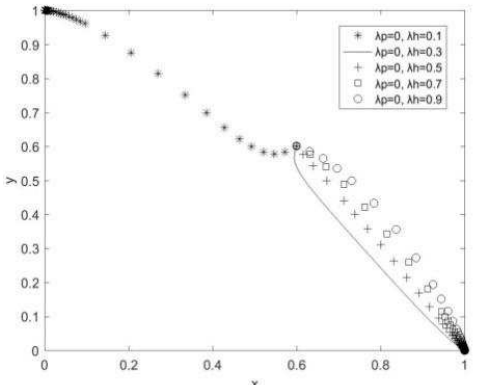

(a). trust action only taken by $\mathrm{HO}$

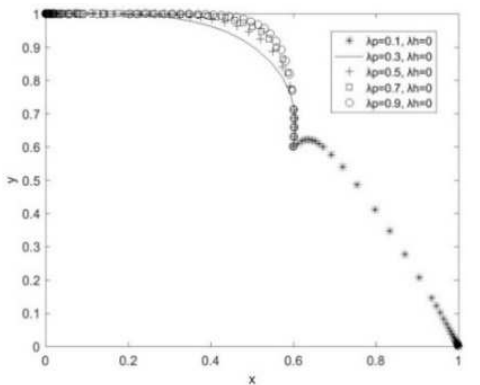

(b). trust action only taken by PS

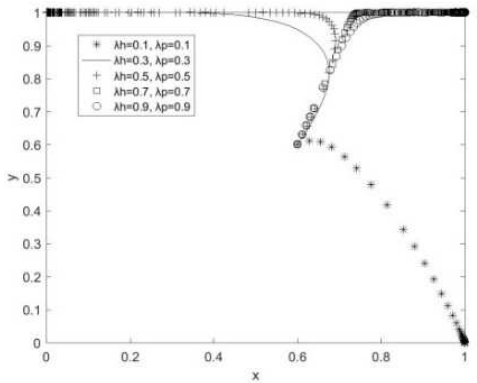

(c). mutual trust

Fig. 8 The evolutionary stable strategies between PSs and HOs

The following conclusions can be summarized. Firstly, when the trust action is only taken by one actor, the trust mechanism has a limited influence on their coordination, which is exhibited in Fig. 8 (a) and (b). More precisely, the coordination strategy is more likely to be adopted by the actor without taking the trust action, while the defection strategy is commonly chosen by the trust player. In this regard, potential benefits have a great influence on their coordination strategy, especially with a high level of trust. Secondly, mutual trust significantly affects the coordinated decision, although it is also determined by the level of trust. Fig.8 (c) denotes that for the small value of $\lambda$ (e.g. $\lambda_{p}=0.3$ and $\lambda_{h}=0.3$ ) and for the large value of $\lambda$ (e.g. $\lambda_{p}=0.7$ and $\lambda_{h}=0.7$ ), the ESSs indicates two heterogeneous states of all PS-players and HO-players. Lu et al. (2018) and Moshtari (2016) showed a better support for such results mentioned onwards.

\subsection{Discussion}

We validated the proposed model with computational studies. These results indicate that the proposed model is effective to capture the coordinated behaviors of PSs and HOs in humanitarian logistics. In this paper, the selection boundary of several scenarios and the influencing factors are comprehensively discussed. Furthermore, the comparison between traditional and trust mechanisms is also analyzed here. Such results provide several managerial insights for decision makers.

Firstly, it should be acknowledged that a lack of better coordination among organizations might result in managerial confusion and ambiguity, even further deteriorating the performance of SHSC (Schulz and Blecken, 2010; Wamsler et al., 2013). As pointed out by Balcik et al. 
567 (2010), a complete commercial relationship or unfair coordination commonly existed in humanitarian logistics but mutual collaboration remained uncommon in the context of disaster, although mutual collaboration has a great impact on the achievement of SHSC, especially between PSs and HOs. Van Wassenhove (2006) also provided powerful evidence for this point. As a result, decision makers should pay more attention to such cases in practical disaster management. Similar viewpoints are also portrayed by the UN in 2015 .

Secondly, different from the existing literature that elaborated the drivers and the advantages of coordination, in this paper, evolutionary game theory is adopted to answer whether to coordinate or not, when to adopt an optimal strategy and how such a strategy can perform well. Indeed, it is popular to adopt the traditional mechanism concerning performance management, so as to analyze the tendency of coordination in a qualitative way. However, such a mechanism is hard to make a difference in the coordination of SHSC, especially when actors fail to obtain the complete information of their opponents in a multi-stage game. Thus, it is necessary to design an analytical tool for disaster managers or decision makers, so as to assist in making decisions. In this paper, an EGM concerning normal returns, coordinated returns and costs, extra returns as well as trust behavior was designed, and it provides practitioners with a clear understanding of how to make decisions concerning HSC coordination. Specially, trust is regarded as potential benefits of attracting attention of coordinated aspiration. For decision makers, the performance management and the relationship management (e.g. trust) should be simultaneously considered in the design of coordination strategy.

Thirdly, results demonstrate that the level of trust play a critical role in promoting the PS-HO partnership. Habit-based trust, competence trust and swift trust are identified as three types of trust, and it is used to evaluate the level of trust (Hung et al., 2004). Swift trust and competence trust are usually implemented in the context of disaster, especially for several actors together with first-contact, different-interest and various-organizational-type features (Tatham and Kovacs, 2010). However, it can only be adopted to manage weak ties of organizational coordination due to a limited influence on the level of trust, which is in line with the insight proposed by Fawcett et al. (2008). On the contrary, Hung et al. (2004) highlighted that habit-based trust could accelerate the establishment of the organization's stronger coordination. It is the accumulated personal knowledge of prior successful interaction that significantly increases 
597

the level of trust and has an essential effect on coordination decisions. Consequently, it can be inferred that a long-term and stable relationship with the concern of undertaking a shared responsibility on inventory management and infrastructure investment might strengthen mutual trust in the context of both disaster and convention. Thus, it provides a better support for disaster managers to design the coordinated strategy.

\section{Conclusions and future research}

SHSC has received an increasing attention from both academics and practitioners. In this paper, we discuss the issue concerning the promotion of HSC coordination from the perspective of the stakeholder approach. After investigating the conflict interests and expectations of PSs and HOs, the tendency of coordinated strategy is analyzed by the EGM, so as to explore coordination decisions regarding whether to coordinate, when and how to adopt an optimal coordinated strategy. Moreover, coordination mechanisms are designed as two EGMs to manage the independence between organizations from the perspective of performance management and relationship theory. Results demonstrate that coordinated strategy was closely related to normal returns, coordinated returns and costs as well as coordinated costs. Moreover, trust is also highlighted as a critical factor to promote coordination.

Results provide several insights on the theory of organizational collaboration in humanitarian logistics regarding sustainability. Firstly, a theoretical link between sustainable principle (stakeholder approach) and organizational coordination is proposed to improve the overall performance of SHSC. Secondly, differing from the hot topic associated with the drivers and the advantages of coordination, this paper aims to design an optimal coordination mechanism to answer whether to coordinate, when and how to adopt a suitable coordinated strategy. In addition to that, the partnership between PSs and HOs is the highlight of this paper, which is different from the recent literature that focuses on network-based coordination and horizontal coordination among the same type of organizations. Thirdly, this paper adopt the EGM to analyze the coordination of SHSC, and the research gap regarding the lack of quantitative study is addressed here.

The limitations of this paper can be summarized as follows. Firstly, only the impact of trust on their coordinated decision is investigated here. The factors regarding green products, green transportation and big data are also critical to achieve the sustainability of HSC, but they are 
627 ignored in this paper. Also, the sustainability of forward humanitarian supply chain is only

discussed here. However, the sustainability of reverse humanitarian supply chain (e.g. disaster debris management) is also important. Secondly, although the sustainability of humanitarian supply chain (e.g. balancing different interests and expectations) can be well achieved by employment of evolutionary game theory, the traditional TBL performance measurement is not mentioned in this paper.

There are valuable topics for further study. Firstly, it is recommended to investigate and illustrate the combination of sustainability and HSC in the future. For example, ethical and green production/transportation should be considered. Besides, the reverse logistics system regarding disaster debris management is an interesting problem, and it needs to be explored from the perspective of sustainability. Secondly, the mathematical programming approach or model might also be an effective method of analyzing the trade-off in HSC coordination, although the EGM performs well in this filed.

\section{Acknowledgements}

This paper was supported by the National Natural Science Foundation of China with Grant No. 71672074 and 71772075, the Twelfth Five-Year Planning Project of Philosophy and Social Science of Guangdong Province with Grant No. GD15CGL07.

\section{Supplementary material}

Supplementary material related to this manuscript consists of Appendix A and B, and is provided as a separate file.

\section{References}

Akhtar, P., Marr, N.E., Garnevska E.V., 2012. Coordination in humanitarian relief chains: chain coordinators. J. Humanit. Logist. Supply Chain Manag. 2(1):85-103.

Altay, N., Green, G.W., 2006. OR/MS research in disaster operations management. Eur. J. Oper. Res. 175(1), 475-493.

Blecken, A., Hellingrath, B., Dangelmaier, W., et al. 2009. A humanitarian supply chain process reference model. International Journal of Services Technology and Management. 12(4), 391-413.

Beamon, B.M., Balcik, B., 2008. Performance measurement in humanitarian relief chains. International Journal of Public Sector Management. 21(1), 4-25.

Balcik, B., Beamon, B.M., Krejci, C.C., et al. 2010. Coordination in humanitarian relief chains: Practices, 
challenges and opportunities. Int. J. Prod. Econ. 126(1), 22-34.

658

Brown. C., Milke, M., Seville, E., 2011b. Disaster waste management following the 2009 Victorian bushfires. Australian Journal of Emergency Management. 26(2), 497-509.

Bealt, J., Barrera, J.C.F., Mansouri, S.A., 2016. Collaborative relationships between logistics service providers and humanitarian organizations during disaster relief operations. Journal of Humanitarian Logistics and Supply Chain Management. 6(2), 118-144.

Cao, C.J., Li, C.D., Yang, Q., et al. 2017. Multi-Objective Optimization Model of Emergency Organization Allocation for Sustainable Disaster Supply Chain. Sustainability. 9(11), doi:10.3390/su9112103.

Cao, C.J., Li, C.D., Yang, Q., et al. 2018. A novel multi-objective programming model of relief distribution for sustainable disaster supply chain in large-scale natural disasters. J. Clean Prod. 174, 1422-1435.

Chen, Y., Ding, S., Zheng, H.D., et al., 2018. Exploring diffusion strategies for mHealth promotion using evolutionary game model. Appl. Math. Comput. 336, 148-161.

Chen, Y.D., Sun, L.Y., 2017. Trust strategy simulation of corporation-NPO cross alliance using evolutionary game theory. Kybernetes. 46(3), 450-465.

Cai, G.S., Kock, N., 2009. An evolutionary game theoretic perspective on e-collaboration: The collaboration effort and media relativeness. Eur. J. Oper. Res. 194(3), 821-833.

Dubey, R., Gunasekaran, A., 2016. The sustainable humanitarian supply chain design: agility, adaptability and alignment. Int. J. Logist.-Res. Appl. 19(1), 62-82.

Dubey, R., Altay, N., Blome, C., 2017. Swift trust and commitment: the missing links for humanitarian supply chain coordination. Ann. Oper. Res. https://doi.org/10.1007/s10479-017-2676-z.

Dubey, R., Altay, N., 2018. Drivers of coordination in humanitarian relief supply chains. In The Palgrave Handbook of Humanitarian Logistics and Supply Chain Management. Palgrave Macmillan, London, 297-325.

Du, L.Y., Qian, L., 2016. The government's mobilization strategy following a disaster in the Chinese context: an evolutionary game theory analysis. Nat. Hazards. 80(3), 1411-1424.

Friedman, D., 1991. Evolutionary games in economics. Econometrica. 59(3), 637-666.

Freeman, R.E., 1984. Strategic Management: A Stakeholder Approach. Pitman: Boston, MA, USA.

Fawcett, S.E., Magnan, G.M., Mccarter, M.W., 2008. Benefits, barriers, and bridges to effective supply chain management. Supply Chain Manag. 13(1), 35-48.

Gimenez, C., Sierra, V., Rodon, J., 2012. Sustainable operations: Their impact on the triple bottom line. Int. J. 
Prod. Econ. 140(1):149-159.

Galindo, G., Batta, R., 2013. Review of recent developments in OR/MS research in disaster operations management. Eur. J. Oper. Res. 230(2), 201-211.

Haavisto, I., Kovacs, G., 2014. Perspectives on sustainability in humanitarian supply chains. Disaster Prev. Manag. 23(5), 610-631.

Hung, Y.T.C., Dennis, A.R., Robert, L., 2004. Trust in virtual teams: towards an integrative model of trust formation. Proceedings of the 37th Hawaii International Conference on System Sciences, 1-11.

Kapucu, N., Garayev, V., Wang, X.H., 2013. Sustaining networks in emergency management: a study of counties in the United States. Public Perform. Manag. Rev. 37(1):104-133.

Kunz, N., Gold, S., 2015. Sustainable humanitarian supply chain management - exploring new theory. Int. J. Logist.-Res. Appl. 20(2), 85-104.

Lu, Q., Goh, M., Souza, R.D., 2018. An Empirical Investigation of Swift Trust in Humanitarian Logistics Operations. J. Humanit. Logist. Supply Chain Manag. 8(1), 70-86.

Liu, J., Xie, K., 2016. Emergency supplies requisition negotiation principle of government in disasters. Kybernetes. 45(8), 1174-1193.

Large, R.O., Thomsen, C.G., 2011. Drivers of green supply management performance: Evidence from Germany. J. Purch. Supply Manag. 17(3):176-184.

Laguna-Salvadó, L., Lauras, M., Okongwu, U., et al., 2018. A multicriteria Master Planning DSS for a sustainable humanitarian supply chain. Ann. Oper. Res, doi:https://doi.org/10.1007/s10479-018-2882-3.

Moshtari, M., 2016. Inter-Organizational Fit, Relationship Management Capability, and Collaborative Performance within a Humanitarian Setting. Prod. Oper. Manag. 25(9), 1542-1557.

Mcevily, B., Perrone, V., Zaheer, A., 2003. Trust as an Organizing Principle. Organ Sci. 14(1), 91-103.

Maon, F., Lindgreen, A., Vanhamme, J., 2009. Developing supply chains in disaster relief operations through cross-sector socially oriented collaborations: a theoretical model. Supply Chain Manag. 14(2), 149-164.

Muñoz-Torres, M.J., Fernandez-Izquierdo, M.A., Rivera-Lirio, J.M., et al., 2018. An Assessment Tool to Integrate Sustainability Principles into the Global Supply Chain. Sustainability. 10(2), doi:10.3390/su10020535.

Nolte, I.M., Boenigk, S., 2011. Public-nonprofit partnership performance in a disaster context: the case of Haiti. Public Adm. 89(4):1385-1402. 
Nurmala, N., de Leeuw, S., Dullaert, W., 2017. Humanitarian-business partnerships in managing humanitarian logistics. Supply. Chain. Manag. 22(1), 82-94.

Oloruntoba, R., Gray, R., 2009. Customer service in emergency relief chains. Int. J. Phys. Distrib. Logist. Manag. 39(6):486-505.

Papadopoulos, T., Gunasekaran, A., Dubey, R., et al., 2017. The role of Big Data in explaining disaster resilience in supply chains for sustainability. J. Clean Prod. 142, 1108-1118.

Rueede, D., Kreutzer, K., 2015. Legitimation Work Within a Cross-Sector Social Partnership. J. Bus. Ethics. 128(1), 39-58.

Stenson, J., 2006. Disaster management as a tool for sustainable development: a case study of cyanide leaching in the gold mining industry. J. Clean Prod. 14(3-4), 230-233.

Schulz, S.F., Blecken, A., 2010. Horizontal cooperation in disaster relief logistics: benefits and impediments. Int. J. Phys. Distrib. Logist. Manag. 40(8/9), 636-656.

Seuring, S., 2013. A review of modeling approaches for sustainable supply chain management. Decis. Support Syst. 54(4), 1513-1520.

Shi, Q., Zhu, J., Li, Q., 2018. Cooperative Evolutionary Game and Applications in Construction Supplier Tendency. Complexity, doi:10.1155/2018/8401813.

Tian, Y.H., Govindan, K., Zhu, Q.H., 2014. A system dynamics model based on evolutionary game theory for green supply chain management diffusion among Chinese manufacturers. J. Clean Prod. 80, 96-105.

Tatham, P., Kovacs, G., 2010. The application of "swift trust" to humanitarian logistics. Int. J. Prod. Econ. $126(1), 35-45$.

United Nations., 2015. The 2030 agenda for sustainable development. https://sustainabledevelopment.un. org/topics/disasterriskreduction.

Van Wassenhove, L.N., 2006. Blackett Memorial Lecture - Humanitarian aid logistics: supply chain management in high gear. J. Oper. Res. Soc. 57(5), 475-489.

Vega, D., Roussat. C., 2015. Humanitarian logistics: the role of logistics service providers. Int. J. Phys. Distrib. Logist. Manag. 45(4), 352-375.

Vega-Mejia, C.A., Montoya-Torres, J.R., Islam, S.M.N., 2017. Consideration of triple bottom line objectives for sustainability in the optimization of vehicle routing and loading operations: a systematic literature review. Ann. Oper. Res, https://doi.org/10.1007/s10479-017-2723-9.

Xu, L., Beamon, B.M., 2006. Supply Chain Coordination and Cooperation Mechanisms: An Attribute-Based 
Approach. J. Supply Chain Manag. 42(1), 4-12.

747 Xie, G., 2016. Cooperative strategies for sustainability in a decentralized supply chain with competing suppliers. J. Clean Prod. 113, 807-821.

749 Yu, H., Zeng, A.Z., Zhao,L., 2009. Analyzing the evolutionary stability of the vendor-managed inventory supply chains. Comput. Ind. Eng. 56(1), 274-282. 


\section{Highlights}

- Organizational coordination problem regarding sustainability of disaster is considered.

- Stakeholder approach is employed to promote partnership between private sector and humanitarian organization.

- Coordination mechanism is captured by quantitative method of evolutionary game model.

- Both traditional and trust mechanisms should be considered in the design of coordination mechanism. 